\title{
Sequential vigilance is unpredictable in reproductive Black-necked Cranes
}

\author{
Yuhang $\mathrm{Li}^{1 \dagger}$, Le Yang ${ }^{2+}$, Yunchao Luo ${ }^{1}$, Yiqian $\mathrm{Wu}^{1}$ and Zhongqiu $\mathrm{Li}^{1 *}$ (1)
}

\begin{abstract}
Background: Vigilance refers to the behavior of animals scanning their surroundings with a main purpose of antipredation. Whether vigilance can serve the function of anti-predation depends on its unpredictability, meaning instantaneous randomness, sequential randomness, and independence, the three assumptions from Pulliam model (J Theor Biol 38:419, 1973). Here we tested two of these three assumptions in reproductive Black-necked Cranes (Grus nigricollis) in Tibetan Plateau: instantaneous randomness and sequential randomness.

Methods: Observations were carried out in July and September of 2014, July and August in 2017 in Selincuo National Nature Reserve, Tibet, with the help of focal sampling method. For instantaneous randomness, we used Kolmogorov-Smirnov test for its negative exponential distribution; for sequential randomness, we used Run test, correlation analysis, and generalized linear model to see if an inter-scan and its previous scan were correlated.

Results: Not similar to some recent studies, we did not find a significant predictable vigilance in this crane. Most inter-scan intervals $(86 / 100,86.0 \%)$ passed negative exponential distribution test, meaning vigilance sequences with instantaneous randomness; most inter-scan intervals (91/100, 91.0\%) passed sequential random test, showing vigilance sequences were random organized.
\end{abstract}

Conclusion: Our results suggest that keeping a vigilance pattern with unpredictability is beneficial to the survival of the Black-necked Cranes, which are facing with both cruel natural environments and high predation risks.

Keywords: Black-necked Cranes, Instantaneous randomness, Sequential randomness

\section{Background}

Animals frequently stop feeding and turn to vigilance status, scanning their surroundings. The primary purpose of this behavior is to detect potential predators (Beauchamp 2014, 2015). If the vigilance has a certain pattern or regularity, or called predictability, it will be known and grasped by a potential predator. Based on this information, the observant predator can make attack adjustments to the predictable vigilance. Therefore, the unpredictability of vigilance has become the baseline for animal individuals to survive from predators.

\footnotetext{
*Correspondence: lizq@nju.edu.cn

†Yuhang Li and Le Yang contributed equally to this work

1 School of Life Sciences, Nanjing University, 163 Xianlin Avenue,

Nanjing 210023, China

Full list of author information is available at the end of the article
}

The Pulliam's vigilance model (Pulliam 1973) was proposed based on three assumptions: instantaneous randomness in scan initiation, sequential randomness in the duration of successive inter-scans, and independent scanning by different group members. Instantaneous randomness and sequential randomness both derive from the assumption that scanning is controlled by a single parameter: the rate of scan initiation (Pulliam 1973; Bednekoff and Lima 1998). Instantaneous randomness means that an individual has the same probability of lifting its head during each instant when its head is down, regardless of how long its head has been down already. An individual scanning in such a manner would produce inter-scan intervals following a negative exponential distribution. Such a distribution has no central tendency or 'hump' but, instead, shows a smoothly decreasing slope as longer intervals become geometrically less likely.

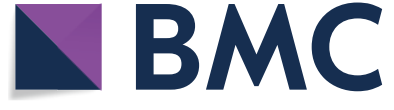

(c) The Author(s) 2018. This article is distributed under the terms of the Creative Commons Attribution 4.0 International License (http://creativecommons.org/licenses/by/4.0/), which permits unrestricted use, distribution, and reproduction in any medium, provided you give appropriate credit to the original author(s) and the source, provide a link to the Creative Commons license, and indicate if changes were made. The Creative Commons Public Domain Dedication waiver (http://creativecommons.org/ publicdomain/zero/1.0/) applies to the data made available in this article, unless otherwise stated. 
Sequential randomness across scans means that scanning process has no 'memory', and the duration of one scan is not influenced by the duration of the previous scan or inter-scan. If a scan depends on its previous scan or inter-scan, the vigilance pattern would become predictable and can be grasped by predators. Sequential randomness or unpredictability can avoid providing observant predators with useful information about when to launch an attack, because there is no predictability in either the initiation of scans or the duration of successive inter-scans (Bednekoff and Lima 1998). In fact, whether the vigilance behavior can be predictable or not has been controversial for a long time. The instantaneous randomness has been found in some studies (Bertram 1980), but still not in others (Lendrem et al. 1986; Beauchamp 2006). The sequential randomness, was similarly supported in some species (Roberts 1994; Suter and Forrest 1994; Li et al. 2017), but not in others (Ferrière et al. 1999; Beauchamp 2006; Pays et al. 2010; Carro et al. 2011).

In this study, we want to test the instantaneous randomness and sequential randomness in reproductive Black-necked Cranes (Grus nigricollis), a big bird living only on plateau (Li and Li 2005). As for the third assumption, we shall discuss in our further works and will not mention in this article. A recent report on these cranes has found that the sequential vigilance was unpredictable when they are wintering in Linzhi County, Tibet (Li et al. 2017). But it remains a question that whether they keep their vigilance unpredictable when they migrate up to a breeding area with higher altitude? Our focal population resides in an extremely cruel habitat, with an elevation of about $4700 \mathrm{~m}$ asl, strong wind, solar radiation, and very limited food resources. Due to its large size, the crane was formerly considered to have few natural enemies, especially for adults (Li and Li 2005). Nevertheless, Feral Dogs (Canis familiaris) have been increasing dramatically in recent decades, and have become a big threat to the cranes (Farrington and Zhang 2013; Kumar and Paliwal 2015). Other predators, including Golden Eagle (Aquila chrysaetos) and Eurasian Lynx (Lynx lynx), are also potential predators in the area. Human disturbance, especially grazing activities, might also affect vigilance of the cranes (Bishop et al. 1998; Bishop and Li 2002; Yang et al. 2016a, b; Che et al. 2018). Therefore, we predict that the reproductive cranes should scan randomly thus to reduce the possibility of being grasped of their vigilance information and therefore being attacked from predators. Two predictions were made according to the two assumptions: (1) a random pattern of inter-scan intervals, thus making a negative exponential distribution; (2) an unrelated relationship between an inter-scan and its previous scan, thus making a random vigilance sequence.

\section{Methods}

\section{Area and species}

Observations were carried out in July and September of 2014, July and August of 2017 in Selincuo National Nature Reserve, Tibet, China $\left(30^{\circ} 59^{\prime} 39.79^{\prime \prime} \mathrm{N}\right.$, $89^{\circ} 06^{\prime} 49.98^{\prime \prime} \mathrm{E}$ ). The reserve was established in 1993 for protecting rare Tibetan wildlife, including Black-necked Cranes, Snow Leopards (Panthera uncia), Tibetan Antelopes (Pantholops hodgsonii). The area is about $1640 \mathrm{~km}^{2}$, with an average elevation of more than $4700 \mathrm{~m}$ asl. The reserve is dominated by the semi-arid monsoon climate with thin air, strong solar radiation, cold and dry climate. The mean temperature is about $8{ }^{\circ} \mathrm{C}$ in summer, but the temperature difference is large. Sometimes it can rise up to more than $20{ }^{\circ} \mathrm{C}$ at noon, and then drops to $0{ }^{\circ} \mathrm{C}$ at night. Summer can be called wet or rainy season since more than $80 \%$ of the total annual precipitation falls in summer. The reserve area is primarily alpine meadows dominated by Sophora moorcroftiana, Ceratostigma minus, Aristida triseta, Orinus thoroldii, Pennisetum centrasiaticum, and Stipa purpurea.

Black-necked Cranes have a global population of about 6600 individuals (Yang et al. 2016a, b). Qinghai-Tibet Plateau is their main breeding area, while the wintering areas are mainly in south-central Tibet, the YunnanGuizhou Plateau in southwest China, India and Bhutan (Qian et al. 2009; Farrington and Zhang 2013; Khan et al. 2014). Black-necked Cranes migrate from wintering areas to the central part of the Selincuo Nature Reserve in early April, breed and live in the reserve until October. Summer cranes have two social units: family groups and social groups. Family groups consist of two adult cranes and one or two nestlings, while social groups are made up of several juveniles.

\section{Behavioral observations}

Every day we drove from a little town Maiba, where we stayed, heading to one of three directions: Xiongmei, Bange, or Shenza, to find the cranes from 9:00 to 18:00. In the process, we recorded every Black-necked Crane that we encountered with focal observation method. After locating the Black-necked Cranes with binoculars (Nikula $8 \times 42$ ), a video camera (Nikon D7100) was used for recording. Each group or individual was recorded for about $20 \mathrm{~min}$. We used tripods throughout the recording process to stabilize the cameras. We stopped recording if any visual disturbances occurred, such as passing human vehicles or large grazing herds. During the reproductive season, the cranes are loyal to their territories ( $\mathrm{Li}$ and $\mathrm{Li}$ 2005). So we recorded the GPS information of each family or individual, thus to avoid resampling same individual on a same day (they all have their own certain territory during reproductive season, especially for those 
Table 1 Goodness-of-fit of inter-scan intervals of reproductive Black-necked Cranes for negative exponential distribution test

\begin{tabular}{|c|c|c|c|c|c|c|c|}
\hline ID & $n$ & $\lambda$ & $p$ & ID & $n$ & $\lambda$ & $p$ \\
\hline $1 \mathrm{~A}$ & 28 & -0.118 & 0.204 & $28 \mathrm{~A}$ & 22 & -0.189 & 0.280 \\
\hline $2 A$ & 31 & - & 0.024 & $29 A$ & 39 & -0.323 & 0.274 \\
\hline $3 A$ & 54 & - & 0.001 & $30 \mathrm{~A}$ & 54 & -0.302 & 0.104 \\
\hline $3 B$ & 30 & -0.100 & 0.508 & $31 A$ & 20 & - & 0.034 \\
\hline $4 \mathrm{~A}$ & 36 & -0.147 & 0.367 & $31 \mathrm{~B}$ & 28 & -0.190 & 0.358 \\
\hline $5 \mathrm{~A}$ & 26 & -0.109 & 0.980 & $31 C$ & 31 & -0.359 & 0.455 \\
\hline $6 \mathrm{~A}$ & 19 & -0.086 & 0.993 & $31 D$ & 41 & -0.238 & 0.580 \\
\hline $7 \mathrm{~A}$ & 19 & -0.049 & 0.163 & $31 \mathrm{E}$ & 30 & -0.112 & 0.751 \\
\hline $7 B$ & 24 & -0.154 & 0.853 & $31 F$ & 51 & - & 0.005 \\
\hline $7 C$ & 19 & -0.079 & 0.616 & $32 \mathrm{~A}$ & 20 & -0.578 & 0.065 \\
\hline $7 D$ & 28 & -0.239 & 0.921 & $32 B$ & 30 & -0.719 & 0.334 \\
\hline $7 \mathrm{E}$ & 29 & -0.216 & 0.341 & $33 \mathrm{~A}$ & 25 & -1.153 & 0.076 \\
\hline $7 F$ & 22 & -0.275 & 0.758 & $34 \mathrm{~A}$ & 26 & -1.044 & 0.862 \\
\hline $7 G$ & 25 & -0.440 & 0.583 & $35 \mathrm{~A}$ & 22 & -0.233 & 0.100 \\
\hline $7 \mathrm{H}$ & 19 & -0.336 & 0.870 & $35 B$ & 20 & -0.298 & 0.985 \\
\hline $8 \mathrm{~A}$ & 38 & -0.303 & 0.214 & $36 \mathrm{~A}$ & 22 & -0.815 & 0.967 \\
\hline $8 B$ & 51 & -0.214 & 0.140 & $36 \mathrm{~B}$ & 27 & -1.472 & 0.059 \\
\hline $9 \mathrm{~A}$ & 27 & -0.089 & 0.232 & $37 \mathrm{~A}$ & 22 & -0.879 & 0.502 \\
\hline $9 \mathrm{~B}$ & 34 & -0.250 & 0.745 & $38 \mathrm{~A}$ & 38 & -1.354 & 0.098 \\
\hline $10 \mathrm{~A}$ & 26 & -0.083 & 0.125 & $38 B$ & 41 & -1.155 & 0.284 \\
\hline $11 \mathrm{~A}$ & 41 & -0.164 & 0.054 & $39 A$ & 43 & -0.248 & 0.217 \\
\hline $12 \mathrm{~A}$ & 49 & - & 0.033 & $39 B$ & 25 & -1.568 & 0.144 \\
\hline $12 B$ & 32 & -0.188 & 0.324 & $40 \mathrm{~A}$ & 27 & -0.455 & 0.428 \\
\hline $13 \mathrm{~A}$ & 31 & -0.415 & 0.270 & $41 \mathrm{~A}$ & 87 & -0.186 & 0.257 \\
\hline $14 A$ & 52 & - & 0.002 & $41 B$ & 84 & - & 0.024 \\
\hline $15 \mathrm{~A}$ & 52 & -0.521 & 0.125 & $42 \mathrm{~A}$ & 40 & -0.443 & 0.524 \\
\hline $16 \mathrm{~A}$ & 43 & -0.356 & 0.386 & $42 B$ & 58 & -0.303 & 0.227 \\
\hline $16 B$ & 95 & - & 0.004 & $43 \mathrm{~A}$ & 32 & -0.276 & 0.180 \\
\hline $17 A$ & 80 & - & 0.001 & $44 \mathrm{~A}$ & 54 & -0.238 & 0.653 \\
\hline $17 \mathrm{~B}$ & 108 & -0.387 & 0.091 & $44 \mathrm{~B}$ & 48 & -0.181 & 0.333 \\
\hline $18 \mathrm{~A}$ & 23 & -0.538 & 0.762 & $45 \mathrm{~A}$ & 23 & -0.266 & 0.736 \\
\hline $19 \mathrm{~A}$ & 30 & -0.216 & 0.517 & $45 B$ & 36 & -0.390 & 0.573 \\
\hline $19 B$ & 28 & -0.216 & 0.617 & $46 \mathrm{~A}$ & 33 & -0.502 & 0.157 \\
\hline $19 \mathrm{C}$ & 43 & - & 0.003 & $46 \mathrm{~B}$ & 42 & -1.241 & 0.106 \\
\hline $19 D$ & 28 & -0.185 & 0.478 & $47 \mathrm{~A}$ & 26 & -0.959 & 0.797 \\
\hline $19 \mathrm{E}$ & 33 & -0.328 & 0.889 & $48 \mathrm{~A}$ & 22 & -0.233 & 0.100 \\
\hline $19 F$ & 27 & -0.111 & 0.329 & $48 \mathrm{~B}$ & 20 & -0.484 & 0.949 \\
\hline $20 \mathrm{~A}$ & 20 & -0.191 & 0.474 & $49 A$ & 23 & -0.830 & 0.728 \\
\hline $21 \mathrm{~A}$ & 23 & -0.381 & 0.398 & $49 B$ & 27 & -1.472 & 0.059 \\
\hline $21 B$ & 50 & - & 0.046 & $49 C$ & 26 & -0.693 & 0.370 \\
\hline $22 A$ & 72 & - & 0.016 & $50 \mathrm{~A}$ & 22 & -0.879 & 0.502 \\
\hline $22 B$ & 48 & -0.198 & 0.436 & $51 A$ & 38 & - & 0.044 \\
\hline $23 \mathrm{~A}$ & 60 & -0.243 & 0.470 & $51 \mathrm{~B}$ & 41 & -1.155 & 0.284 \\
\hline $23 B$ & 47 & -0.181 & 0.838 & $52 \mathrm{~A}$ & 42 & -0.242 & 0.157 \\
\hline $24 \mathrm{~A}$ & 39 & -0.138 & 0.311 & $52 \mathrm{~B}$ & 24 & -1.546 & 0.174 \\
\hline $24 B$ & 55 & -0.148 & 0.834 & $53 \mathrm{~A}$ & 29 & -0.195 & 0.298 \\
\hline $25 \mathrm{~A}$ & 40 & -0.837 & 0.098 & $54 \mathrm{~A}$ & 20 & -0.146 & 0.454 \\
\hline $25 B$ & 33 & - & 0.021 & $54 \mathrm{~B}$ & 26 & -0.101 & 0.140 \\
\hline $26 \mathrm{~A}$ & 26 & -1.522 & 0.055 & $55 \mathrm{~A}$ & 26 & -0.080 & 0.347 \\
\hline $27 \mathrm{~A}$ & 28 & -0.992 & 0.154 & $55 \mathrm{~B}$ & 21 & -0.366 & 0.519 \\
\hline
\end{tabular}

Significant cases were in italics. While numbers represent the group number and the letters represent the individuals from the same group 
families that carry nestlings and were about to have nestlings, so it is basically impossible that one same family was sampled on more than one occasion). Weather, day time, group type and group size were also recorded at the same time. Observations were only made on sunny or cloudy days thus to avoid potential effect of bad weathers.

\section{Data analysis}

A focal observation includes a sequence of scans and inter-scans. We totally collected 208 focal samples with a total time of about $2400 \mathrm{~min}$. Samples less than $10 \mathrm{~min}$, or with less than 20 feeding/vigilance transitions, or with visible disturbances were deleted, and thus 100 samples from 55 groups were left. We reviewed all these samples and timed scans and inter-scans to the nearest $1 \mathrm{~s}$.

For instantaneous randomness, we used KolmogorovSmirnov test to examine the distribution of inter-scans of each vigilance sequence. We considered the inter-scan intervals were randomly organized if they passed the negative exponential distribution test, and then we calculated its parameter $\lambda$, which was the only determinant of the distribution.

Since most sequences of our samples included less than 30 transitions, we tested sequential randomness of interscan intervals with nonparametric one-sample runs test (Beauchamp 2006). Median value was set as the cut point. This test was used to assess whether long ( $>$ median value) or short (<median value) inter-scans occurred together in the sequence more often than expected by chance. Rejection of random test provides evidence for a nonrandom pattern of vigilance sequence. We also used a generalized linear model to assess whether every interscan interval was dependent on the previous scan duration (Pays et al. 2010). The previous scan duration was set as an independent variable. Family or group ID was set as a random factor. For each independent sample, we also used Pearson correlation when data were normally distributed or Spearman rank correlation when data were not normally distributed to evaluate whether the inter-scan intervals and the previous scan durations were closely related (Li et al. 2017).

All statistical analyses were carried out with SPSS (version 20.0). The level of statistical significance was set at $p=0.05$, and data were reported as mean $\pm \mathrm{SE}$.

\section{Results}

We totally included 100 vigilance sequences in our database; the average duration of inter-scan intervals was $20.3 \pm 0.4 \mathrm{~s}$, ranging from 1 to $331 \mathrm{~s}$, whereas the average scan duration was $6.6 \pm 0.3 \mathrm{~s}$, ranging from 1 to $215 \mathrm{~s}$. For the instantaneous randomness, 86 sequences passed Kolmogorov-Smirnov test for the negative exponential distribution, meaning that $86.0 \%$ sequences interrupted feeding and scanned their surroundings randomly. The parameters of each negative exponential function were shown in Table 1, and the grouped inter-scan intervals were shown as Fig. 1.

For the sequential randomness, runs tests revealed that most sequences of inter-scan intervals (91/100, 91.0\%) could be considered as non-significant correlation or random organized, and only 9 sequences were in nonrandom order (Table 2). The correlation analysis between the previous scan and the current inter-scan also showed an unpredictable correlation in most cases (92/100, 92.0\%). Only 8 sequences showed a negative or positive correlation (Table 2). From the generalized linear model, there was no significant correlation between the previous scan and the current inter-scan $\left(F_{1,3489}=3.212, p=0.0732\right)$, although the group ID had a significant effect on interscan intervals $\left(F_{99,3489}=4.939, p<0.001\right)$.

\section{Discussion}

The randomness or unpredictability is probably the baseline of whether vigilance can serve its main function of anti-predation. We tested the two main assumptions of the classical group-size-effect model proposed by Pulliam in 1973, namely the instantaneous randomness and the sequential randomness. Our results showed that most of the inter-scan intervals of the Black-necked Cranes can be considered as randomly organized.

Instantaneous or sequential randomness of vigilance did not receive supports from most recent studies (Beauchamp 2006; Pays et al. 2010; Carro et al. 2011), but it did from some other studies (Bertram 1980; Li et al. 2017), just like what we found in this study of reproductive Black-necked Cranes. Actually, using a random or regulative strategy for a vigilant animal is probably depending

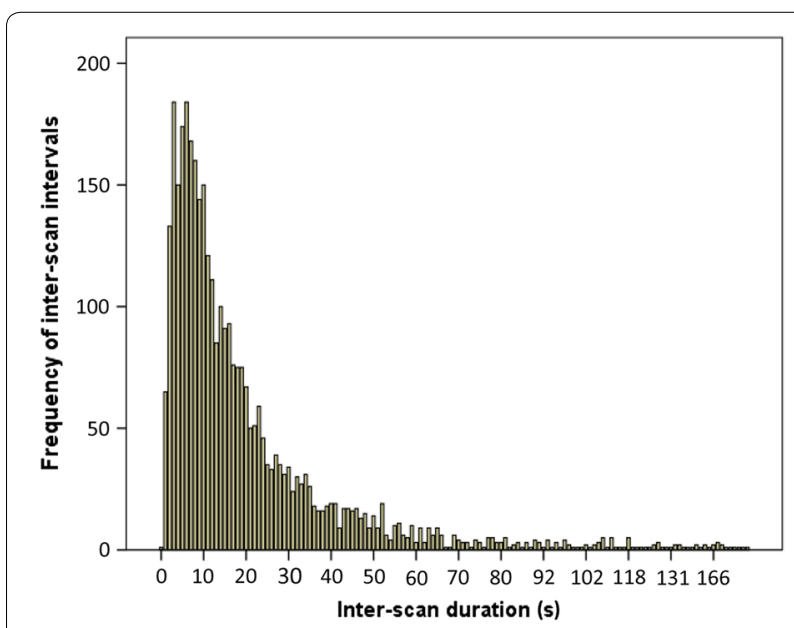

Fig. 1 Frequency of inter-scan intervals obtained from 100 individual behavioral sequences of reproductive Black-necked Cranes in Selincuo National Nature Reserve, Tibet 
Table 2 Run test and correlation test of inter-scan intervals and scan durations in reproductive Black-necked Cranes in Tibet

\begin{tabular}{|c|c|c|c|c|c|c|c|c|c|c|c|}
\hline \multirow[t]{2}{*}{ ID } & \multirow[t]{2}{*}{$n$} & \multicolumn{2}{|l|}{ Run } & \multicolumn{2}{|c|}{ Correlation } & \multirow[t]{2}{*}{ ID } & \multirow[t]{2}{*}{$n$} & \multicolumn{2}{|l|}{ Run } & \multicolumn{2}{|c|}{ Correlation } \\
\hline & & $z$ & $p$ & $r$ & $p$ & & & $z$ & $p$ & $r$ & $p$ \\
\hline $1 \mathrm{~A}$ & 28 & -0.940 & 0.347 & 0.153 & 0.437 & $28 \mathrm{~A}$ & 22 & -0.655 & 0.512 & 0.251 & 0.260 \\
\hline $2 \mathrm{~A}$ & 31 & -1.457 & 0.145 & 0.239 & 0.196 & $29 \mathrm{~A}$ & 39 & -0.289 & 0.773 & 0.071 & 0.669 \\
\hline $3 \mathrm{~A}$ & 54 & -0.550 & 0.583 & -0.034 & 0.808 & $30 \mathrm{~A}$ & 54 & -1.239 & 0.215 & -0.037 & 0.792 \\
\hline $3 B$ & 30 & -1.301 & 0.193 & -0.383 & 0.037 & $31 \mathrm{~A}$ & 20 & 0.689 & 0.491 & 0.371 & 0.107 \\
\hline $4 A$ & 36 & -2.198 & 0.028 & 0.131 & 0.447 & $31 B$ & 28 & 0.000 & 1.000 & -0.047 & 0.811 \\
\hline $5 \mathrm{~A}$ & 26 & -0.976 & 0.329 & -0.272 & 0.179 & $31 C$ & 31 & -1.726 & 0.084 & -0.063 & 0.736 \\
\hline $6 \mathrm{~A}$ & 19 & -0.935 & 0.350 & -0.252 & 0.298 & 310 & 41 & -0.313 & 0.755 & 0.060 & 0.709 \\
\hline $7 \mathrm{~A}$ & 19 & 0.486 & 0.627 & 0.411 & 0.080 & $31 \mathrm{E}$ & 30 & 0.186 & 0.853 & -0.243 & 0.196 \\
\hline $7 B$ & 24 & -0.626 & 0.531 & 0.139 & 0.516 & $31 \mathrm{~F}$ & 51 & -1.253 & 0.210 & -0.188 & 0.186 \\
\hline $7 C$ & 19 & 0.012 & 0.990 & 0.324 & 0.176 & $32 \mathrm{~A}$ & 20 & 0.279 & 0.781 & -0.180 & 0.447 \\
\hline $7 D$ & 28 & -0.553 & 0.580 & -0.232 & 0.235 & $32 B$ & 30 & -0.929 & 0.353 & -0.200 & 0.289 \\
\hline $7 E$ & 29 & 0.000 & 1.000 & -0.261 & 0.171 & $33 A$ & 25 & -2.000 & 0.046 & 0.340 & 0.097 \\
\hline TF & 22 & -1.529 & 0.126 & -0.548 & 0.008 & $34 A$ & 26 & -3.403 & 0.001 & 0.013 & 0.948 \\
\hline $7 G$ & 25 & -0.810 & 0.418 & -0.183 & 0.381 & $35 \mathrm{~A}$ & 22 & -1.092 & 0.275 & 0.102 & 0.653 \\
\hline $7 \mathrm{H}$ & 19 & 0.486 & 0.627 & -0.211 & 0.387 & $35 B$ & 20 & -0.689 & 0.491 & 0.226 & 0.337 \\
\hline $8 \mathrm{~A}$ & 38 & 0.000 & 1.000 & 0.140 & 0.400 & $36 \mathrm{~A}$ & 22 & -1.503 & 0.133 & -0.186 & 0.408 \\
\hline $8 B$ & 51 & 0.860 & 0.390 & 0.097 & 0.498 & $36 B$ & 27 & 0.793 & 0.428 & -0.035 & 0.864 \\
\hline $9 \mathrm{~A}$ & 27 & -0.779 & 0.436 & 0.202 & 0.311 & $37 A$ & 22 & 1.583 & 0.113 & 0.200 & 0.372 \\
\hline $9 B$ & 34 & -0.174 & 0.862 & 0.018 & 0.918 & $38 \mathrm{~A}$ & 38 & -1.480 & 0.139 & -0.022 & 0.895 \\
\hline $10 \mathrm{~A}$ & 26 & -1.001 & 0.317 & -0.197 & 0.334 & $38 B$ & 41 & 1.499 & 0.134 & -0.151 & 0.345 \\
\hline $11 \mathrm{~A}$ & 41 & 1.270 & 0.204 & -0.331 & 0.034 & $39 A$ & 43 & -1.850 & 0.064 & -0.381 & 0.012 \\
\hline $12 \mathrm{~A}$ & 49 & -0.509 & 0.611 & -0.075 & 0.608 & $39 B$ & 25 & -0.340 & 0.734 & -0.019 & 0.927 \\
\hline $12 B$ & 32 & -0.898 & 0.369 & -0.361 & 0.042 & $40 \mathrm{~A}$ & 27 & -0.779 & 0.436 & 0.151 & 0.452 \\
\hline $13 \mathrm{~A}$ & 31 & -0.726 & 0.468 & 0.058 & 0.755 & $41 \mathrm{~A}$ & 87 & -1.617 & 0.106 & -0.124 & 0.253 \\
\hline $14 A$ & 52 & -1.961 & 0.050 & -0.057 & 0.688 & $41 \mathrm{~B}$ & 82 & -0.439 & 0.660 & -0.169 & 0.130 \\
\hline $15 \mathrm{~A}$ & 52 & 0.011 & 0.991 & 0.300 & 0.031 & $42 \mathrm{~A}$ & 40 & -1.762 & 0.078 & -0.161 & 0.320 \\
\hline $16 \mathrm{~A}$ & 43 & -1.232 & 0.218 & -0.066 & 0.673 & $42 B$ & 58 & -0.762 & 0.446 & 0.091 & 0.499 \\
\hline $16 B$ & 95 & -3.346 & 0.001 & 0.110 & 0.288 & $43 \mathrm{~A}$ & 32 & -0.539 & 0.590 & -0.048 & 0.794 \\
\hline $17 \mathrm{~A}$ & 80 & -1.500 & 0.134 & -0.037 & 0.747 & $44 \mathrm{~A}$ & 54 & -0.815 & 0.415 & 0.036 & 0.795 \\
\hline $17 \mathrm{~B}$ & 108 & -1.094 & 0.274 & -0.148 & 0.126 & $44 B$ & 48 & -0.134 & 0.893 & -0.182 & 0.215 \\
\hline $18 \mathrm{~A}$ & 23 & -0.846 & 0.398 & -0.654 & 0.001 & $45 \mathrm{~A}$ & 23 & 0.000 & 1.000 & -0.296 & 0.170 \\
\hline $19 \mathrm{~A}$ & 30 & 0.212 & 0.832 & 0.152 & 0.422 & $45 B$ & 36 & -2.536 & 0.011 & -0.311 & 0.069 \\
\hline $19 \mathrm{~B}$ & 28 & -0.193 & 0.847 & -0.110 & 0.576 & $46 \mathrm{~A}$ & 33 & 0.713 & 0.476 & -0.076 & 0.676 \\
\hline $19 C$ & 43 & -0.305 & 0.760 & -0.039 & 0.805 & $46 B$ & 42 & -1.299 & 0.194 & 0.075 & 0.636 \\
\hline $19 D$ & 28 & 1.383 & 0.167 & -0.064 & 0.745 & $47 A$ & 26 & -3.002 & 0.003 & -0.242 & 0.233 \\
\hline $19 \mathrm{E}$ & 33 & -0.225 & 0.822 & 0.022 & 0.904 & $48 \mathrm{~A}$ & 22 & -1.092 & 0.275 & 0.102 & 0.653 \\
\hline $19 F$ & 27 & 1.580 & 0.114 & -0.285 & 0.150 & $48 \mathrm{~B}$ & 20 & -0.689 & 0.491 & 0.035 & 0.883 \\
\hline $20 \mathrm{~A}$ & 20 & -0.230 & 0.818 & 0.060 & 0.801 & $49 \mathrm{~A}$ & 23 & -1.653 & 0.098 & -0.270 & 0.212 \\
\hline $21 \mathrm{~A}$ & 23 & -0.846 & 0.398 & -0.094 & 0.670 & $49 B$ & 27 & 0.793 & 0.428 & -0.035 & 0.864 \\
\hline $21 B$ & 50 & -1.429 & 0.153 & -0.269 & 0.059 & $49 C$ & 26 & -0.573 & 0.566 & 0.206 & 0.314 \\
\hline $22 \mathrm{~A}$ & 70 & -0.963 & 0.335 & -0.216 & 0.072 & $50 \mathrm{~A}$ & 22 & 1.583 & 0.113 & 0.122 & 0.589 \\
\hline $22 \mathrm{~B}$ & 48 & 0.146 & 0.884 & 0.039 & 0.791 & $51 \mathrm{~A}$ & 38 & -1.480 & 0.139 & -0.046 & 0.782 \\
\hline $23 A$ & 60 & -2.604 & 0.009 & 0.205 & 0.116 & $51 \mathrm{~B}$ & 41 & 1.499 & 0.134 & -0.151 & 0.345 \\
\hline $23 B$ & 47 & 0.003 & 0.997 & -0.109 & 0.464 & $52 A$ & 42 & -1.718 & 0.086 & -0.346 & 0.025 \\
\hline $24 \mathrm{~A}$ & 39 & -0.970 & 0.332 & -0.044 & 0.788 & $52 B$ & 24 & -0.175 & 0.861 & -0.009 & 0.966 \\
\hline $24 B$ & 55 & -2.312 & 0.021 & 0.014 & 0.917 & $53 \mathrm{~A}$ & 29 & 0.007 & 0.995 & -0.345 & 0.067 \\
\hline $25 \mathrm{~A}$ & 40 & -1.442 & 0.149 & -0.223 & 0.167 & $54 \mathrm{~A}$ & 20 & -0.230 & 0.818 & -0.147 & 0.536 \\
\hline $25 B$ & 33 & -0.349 & 0.727 & -0.144 & 0.423 & $54 \mathrm{~B}$ & 26 & -0.600 & 0.548 & 0.012 & 0.955 \\
\hline $26 \mathrm{~A}$ & 26 & -0.170 & 0.865 & -0.047 & 0.821 & $55 \mathrm{~A}$ & 26 & -0.976 & 0.329 & 0.054 & 0.793 \\
\hline $27 \mathrm{~A}$ & 28 & -0.871 & 0.384 & 0.116 & 0.558 & $55 \mathrm{~B}$ & 21 & 0.011 & 0.991 & -0.039 & 0.868 \\
\hline
\end{tabular}

Significant cases were in italics. While numbers represent the group number and the letters represent the individuals from the same group 
on their environmental surroundings, especially the predation risk. If feeding is too risky, especially with stalking predators present, animals will make themselves unpredictable; otherwise detection of predation risk should be achieved better by regular scanning. In former studies that rejected vigilance randomness, there were no natural enemies for Greater Flamingos (Phoenicopterus ruber ruber) (Beauchamp 2006) and Greater Rheas (Rhea Americana) (Carro et al. 2011) in South America. These large birds are sensitive to human disturbance (Galicia and Baldassarre 1997; Baldassarre and Arengo 2000; Yosef 2000); however, human disturbance is not like a stalking predation threat in an open landscape of water or grassland. In this case, regular scanning for human disturbance would be a better option and therefore about half of their vigilance sequences can be predicted.

Comparably, although Black-necked Crane is also a large bird, its surviving environments are extremely cruel. The cranes mostly form a family group with only two members during the reproductive season, thus leading to a much smaller group than Greater Flamingos or Greater Rheas. They not only need to survive from high altitude, low temperature, thin air and starvation, and take care of their offspring, but also need to face threatens from human or stalking predators such as Eurasian Lynx. And even non-stalking predators such as stray dogs could adopt a stalking strategy to catch local birds (Li et al. 2017; Yang et al. 2019). Therefore, keeping vigilance unpredictable was very essential for the survival of these rare Black-necked Cranes.

\section{Conclusion}

Similar to our previous findings during winter period (Li et al. 2017; Che et al. 2018), Black-necked Cranes also kept their vigilance unpredictable during the breeding season, meaning that both instantaneous randomness and sequential randomness were supported. Keeping a vigilance pattern with randomness or unpredictability is beneficial to the survival and reproduction of the Black-necked Cranes, which are facing with both cruel natural environments and high predation risks.

\section{Authors' contributions}

LY, Y. Li, Y. Luo and YW did the field survey and collected data. Y. Li and ZL analyzed data. Y. Li and LY drafted the paper. ZL reviewed and edited the paper. All authors read and approved the final manuscript.

\section{Author details}

1 School of Life Sciences, Nanjing University, 163 Xianlin Avenue, Nanjing 210023, China. ${ }^{2}$ Tibet Plateau Institute of Biology, 19 Beijing West Road, Lhasa 850000, China.

\section{Acknowledgements}

We thank Wang Lin and Jiabu for their help with fieldwork.

\section{Competing interests}

The authors declare that they have no competing interests.

\section{Availability of data and materials}

The datasets used and/or analyzed during the current study are available from the corresponding author on reasonable request.

\section{Consent for publication}

Not applicable.

\section{Ethical approval}

This is an observational study; all observations were made 300 m away from the focal animals to minimize observer effects. All the observational procedures in this study were approved by the Chinese Wildlife Management Authority.

\section{Funding}

This work was financially supported by the National Natural Science Foundation of China (Nos. 31360141, 31772470, and No. J1103512), the West Light Foundation of Chinese Academy of Sciences (2015), and the Project of National Biodiversity Observation Network-Bird (2015-2018).

Received: 7 June 2018 Accepted: 6 December 2018

Published online: 10 December 2018

\section{References}

Baldassarre G, Arengo F. A review of the ecology and conservation of caribbean flamingos in Yucatan, Mexico. Waterbirds. 2000;23:70-9.

Beauchamp G. Nonrandom patterns of vigilance in flocks of the greater flamingo, Phoenicopterus ruber ruber. Anim Behav. 2006;71:593-8.

Beauchamp G. Social predation: How group living benefits predators and prey. London: Academic Press; 2014.

Beauchamp G. Animal vigilance: monitoring competitors and predators. Oxford: Academic Press; 2015.

Bednekoff PA, Lima SL. Randomness, chaos and confusion in the study of antipredator vigilances. Trends Ecol Evol. 1998;13:284-7.

Bertram B. Vigilance and group size in ostriches. Anim Behav. 1980;28:278-86.

Bishop MA, Li F. Effects of farming practices in Tibet on wintering Blacknecked Crane (Grus nigricollis) diet and food availability. Chin Biodivers. 2002;10:393-8.

Bishop MA, Zhouma C, Yanling S, Harkness J, Binyuan G. Winter habitat use by Black-necked Cranes Grus nigricollis in Tibet. Wildfowl. 1998;49:228-41.

Carro ME, Fernández GJ, Reboreda JC. Sequential predictability of the scanning behaviour of greater rheas, Rhea americana. Ethol Ecol Evol. 2011;23:27-39.

Che Y, Yang L, Li ZQ. A study on vigilance synchronization of wintering blacknecked cranes (Grus nigricollis) family in Tibet, China. Acta Ecol Sinica. 2018;38(4):1375-81 (in Chinese).

Farrington J, Zhang X. The black-necked cranes of the Longbao National Nature Reserve, Qinghai, China: current status and conservation issues. Mt Res Dev. 2013:33:305-13.

Ferrière R, Cazelles B, Cézilly F, Desportes J. Predictability, chaos and coordination in bird vigilant behaviour. Anim Behav. 1999;57:497-500.

Galicia E, Baldassarre G. Effects of motorized tourboats on the behavior of nonbreeding american flamingos in Yucatan, Mexico. Conserv Biol. 1997;11:1159-65

Khan A, Chandan P, Takpa J, Hussain SA, Rattan R, Jamwal PS, Ahmad T. Diurnal time budget of breeding Black-necked Crane (Grus nigricollis) in Changthang, Ladakh, India. Zool Res. 2014;35(S1):158-66.

Kumar A, Paliwal R. Feral dogs of Spiti Valley, Himachal Pradesh: an emerging threat for wildlife and human life. Curr Sci. 2015;108:1799-800.

Lendrem D, Stretch D, Metcalfe N, Jones P. Scanning for predators in the purple sandpiper-a time-dependent or time-independent process. Anim Behav. 1986:34:1577-8.

Li F, Li Z. Research on black-necked crane. Shanghai: Shanghai Scientific and Technological Education Publishing House; 2005.

Li Z, Che Y, Yang L. Can sequential vigilance be predicted? Behav Process. 2017;145:81-5. 
Pays $\mathrm{O}$, Blomberg S, Renaud P, Favreau F, Jarman P. How unpredictable is the individual scanning process in socially foraging mammals? Behav Ecol Sociobiol. 2010;64:443-54.

Pulliam H. On the advantages of flocking. J Theor Biol. 1973;38:419.

Qian F, Wu H, Gao L, Zhang H, Li F, Zhong X, Yang X, Zheng G. Migration routes and stopover sites of Black-necked Cranes determined by satellite tracking. J Field Ornithol. 2009;80:19-26.

Roberts G. When to scan: an analysis of predictability in vigilance sequences using autoregression models. Anim Behav. 1994:48:579-85.

Suter R, Forrest T. Vigilance in the interpretation of spectral analyses. Anim Behav. 1994:48:223-5.
Yang L, Li J, Tsamchu D. Number and distribution of wintering Black-necked Crane (Grus nigricollis) in drainage area of Yarlung Zangbo River and its two branches from Tibet. J Northeast For Univ. 2016a;44(5):72-4 (in Chinese).

Yang L, Zhuom C, Li Z. Group size effects on vigilance of wintering Black-necked Cranes (Grus nigricollis) in Tibet, China. Waterbirds. 2016b;39:108-13.

Yang L, Cao P, Li Z, Dang W. Damage and control of free-ranging dogs in Tibet. J Biol. 2019;36(2) (in Chinese) (in press).

Yosef R. Individual distances among greater flamingos as indicators of tourism pressure. Waterbirds. 2000;23:26-31.
Ready to submit your research? Choose BMC and benefit from:

- fast, convenient online submission

- thorough peer review by experienced researchers in your field

- rapid publication on acceptance

- support for research data, including large and complex data types

- gold Open Access which fosters wider collaboration and increased citations

- maximum visibility for your research: over 100M website views per year

At BMC, research is always in progress.

Learn more biomedcentral.com/submissions 